\title{
Endourological Management of Iatrogenic Ureterovaginal Fistula following Obstetric and Gynecological Surgeries at Tertiary Referral Center
}

\author{
Amit Mani Upadhyay ${ }^{1}$, Bigyan Acharya ${ }^{1}$, Ashok Kumar Kunwar ${ }^{1}$, Kabir Tiwari $^{1}$, Sanjesh Bhakta Shrestha ${ }^{1}$, \\ Hema Kumari Pradhan ${ }^{2}$, Ganesh Dangal ${ }^{2}$ \\ ${ }^{1}$ Department of General Surgery and Urology, \\ ${ }^{2}$ Department of Obstetrics and Gynecology: phect-NEPAL/ Kathmandu Model Hospital, Nepal
}

Received: May 20, 2020

Accepted: May 31, 2020

\section{ABSTRACT}

\begin{abstract}
Aims: To evaluate the outcome of endourological management of iatrogenic ureterovaginal fistula caused by gynecological and obstetric surgeries.

Methods: This is a retrospective analysis of uretorovaginal fistula (UVF) patients who underwent UVF management with endourology technique from February 2014 to November 2019. All data were taken from fistula database. All non-obstetric/gynaecological cases and open surgical procedures leading to UVF were excluded. Diagnostic evaluation by cystoscopy and ureterorenoscopy; and use of guide wire, C-arm and DJ stent were recorded. Three to six months post-operative follow up status was also recorded.
\end{abstract}

Results: There were 14 cases managed by retrograde DJ stenting. Both hysterectomy $(n=10)$ and Cesarean Sections ( $\mathrm{n}=4)$ were the past surgeries. Diagnosis was made by history, methylene blue test, cystoscopy, intravenous urography and CT urogram. Treatment was retrograde DJ stenting. All of them had unilateral distal ureteric injury close to vesicoureteric junction leading to ureterovaginal fistula. All were continent at the end.

Conclusions: Endourological approach with retrograde DJ stenting had successful outcome in iatrogenic UVF.

Keywords: double J stent, endourological technique, iatrogenic ureterovaginal fistula, ureterorenoscope.

Citation : Upadhyay AM, Acharya B, Kunwar AK,Tiwari K,Shrestha SB, Pradhan HK, et al. Endourological Management of Iatrogenic Ureterovaginal Fistula following Obstetric and Gynecological Surgeries at Tertiary Referral Center. Nep J Obstet Gynaecol. 2020;15(30):62-67. DOI: 10.3126/njog.v15i1.29344

\section{INTRODUCTION}

An abnormal communication between the ureter and vagina is defined as ureterovaginal fistula (UVF), which results in incontinence of urine, obstructive uropathy, and if not recognized and treated earlier, may lead to permanent kidney damage. It is very difficult to identify ureteric injury during open or laparoscopic surgeries and it is suspected in the postoperative period only when the patient starts leaking urine per vagina. ${ }^{1,2}$ Patients with UVF generally present with leakage of urine per vagina, however, majority of them have normal course of micturition. Iatrogenic ureteric injury which leads to formation of UVF often occurs in $0.5-2.5 \%$ of major

\section{CORRESPONDENCE}

Dr Amit Mani Upadhyay

Department of General Surgery

phect-NEPAL /Kathmandu Model Hospital, Exhibition Road,

Kathmandu, Nepal.

Email: amitmaniupadhyay@gmail.com; Phone: +977-9841281812 gynecological and obstetric surgical procedures. Hysterectomy (open or laparoscopic) being the most common cause followed by cesarean section. ${ }^{3,4}$ Majority of UVF occur 1-4 weeks after hysterectomy done for benign rather than malignant pathology and followed by cesarean section, cystocele repair and procedure for infertility. ${ }^{5,6}$ Morbidity associated with UVF are prolonged hospital stay, obstructive uropathy, secondary surgical intervention, and detrimental effect on the women's quality of life..$^{7,8}$ The aim of this study was to evaluate the endoscopic surgical procedure and its clinical efficacy in the management of ureterovaginal fistula (UVF). 


\section{METHODS}

This is a retrospective analysis of 14 patients who underwent UVF management with endourology technique. All the cases were referred from other centersto Department of Obstetrics and Gynecology, phect-NEPAL/Kathmandu Model Hospital. Study period was from February 2014 to November 2019. Ethical clearance was obtained from hospital's institutional review committee (IRC). Data were taken from fistula data base maintained in the hospital. Total 30 cases of UVF managed in our hospital were identified. Patients, who developed ureterovaginal fistula following obstetric or gynecological surgeries, managed endourologically were included in the study. Other cases of iatrogenic ureteric injuries and open procedures for management of UVF were excluded from the study. The diagnostic and treatment procedures were recorded. The success of the treatment was evaluated in terms of immediate cessation of leakage of urine per vagina, continent after removal of Foley catheter with restoration of satisfactory renal function on follow up.

\section{RESULTS}

Fistula database revealed 30 cases of UVF and 14 were due to past OB-GYN surgery who underwent endourological procedure. Age of the patients ranged from 19 to 55 years with mean age of 38 years. Out of 14 cases 10 had past cesarean section and 4 had gynecological surgery like total abdominal hysterectomy (TAH) and total laparoscopic hysterectomy (TLH) [Table-1].

Table-1: Causes of ureterovaginal fistula managed endourologically $(n=14)$

\begin{tabular}{|c|c|c|}
\hline Previous Surgery & Frequency & Percentage \\
\hline Gynaecological Procedures & 10 & 71.43 \\
\hline TAH & 8 & 57.14 \\
\hline TLH & 2 & 14.29 \\
\hline Obstetric Emergencysurgeries & 4 & 28.57 \\
\hline LSCS & 2 & 14.29 \\
\hline LSCS for obstructed labor & 2 & 14.29 \\
\hline & & \\
\hline
\end{tabular}

Onset of urine leakage per vagina following primary surgery ranged from 1 to 23 days (median 7days) and was referred to this center within 30 days from primary surgery. CT urogram was done in 8 patients and intravenous urography (IVU) was done in 6 patients to confirm the preoperative diagnosis.All of them had distal ureteric injury close to vesicoureteric junction leading to ureterovaginal fistula. All patients had unilateral distal ureteric injury, 9 (64\%) were left and 5(36\%) were right ureter. All patients were managed with cystoscopy, diagnostic ureterorenoscopy followed by retrograde DJ stenting. They were almost dry after the procedure with no requirement of peri pads in the post-operative ward. Foley catheter was removed after 48 hours. The median hospital stay of the patient was 6 days (range $=2-21$ ). Postoperative period was uneventful with 12 patients having minor problem (Clavien-dindo grade I) and two had recurrent urinary tract infection (Clavien- dindo grade II), which was managed by intravenous antibiotics.

The diagnosis of ureterovaginal fistula was established from clinical history, physical examination, negative methylene blue dye test and with demonstration of extravasation of contrast medium from the ureter in intravenous urography or CT urogram study [Figure-1].

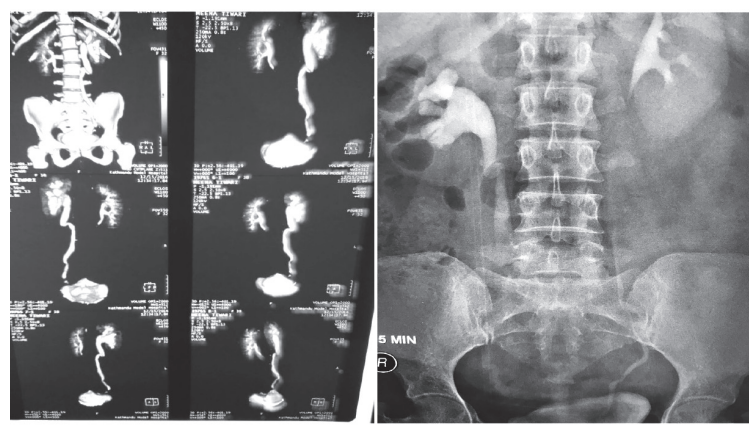

Figure-1: CT urogram showing left ureterovaginal fistula with extravasations of dye at the left distal ureter [Left] and IVU of patient showing right ureterovaginal fistula [Right]

Ultrasonography of abdomen and pelvis was done in all patients.Routine laboratory blood investigations, urine analysis, and urine culture were sent for all patients. All the patients were admitted two days prior to surgery. A prophylactic intravenous antibiotic, as per urine culture and sensitivity report, was given to all patients 24 hours prior to surgery. All these patients were evaluated with cystoscopy followed by diagnostic ureterorenoscopy (URS) to see fistula opening [Figure-2]. A 0.035 " size terrumo guide wire was inserted and its proper position in the system was confirmed by C-arm. In some cases, URS assisted dilatation of the ureter was needed 
Endourological Management of Iatrogenic Ureterovaginal Fistula

to negotiate the guide wire proximal to fistula site. Retrograde pyelogram (RPG) was performed in all the patients to rule out insertion of stent into a false passage.

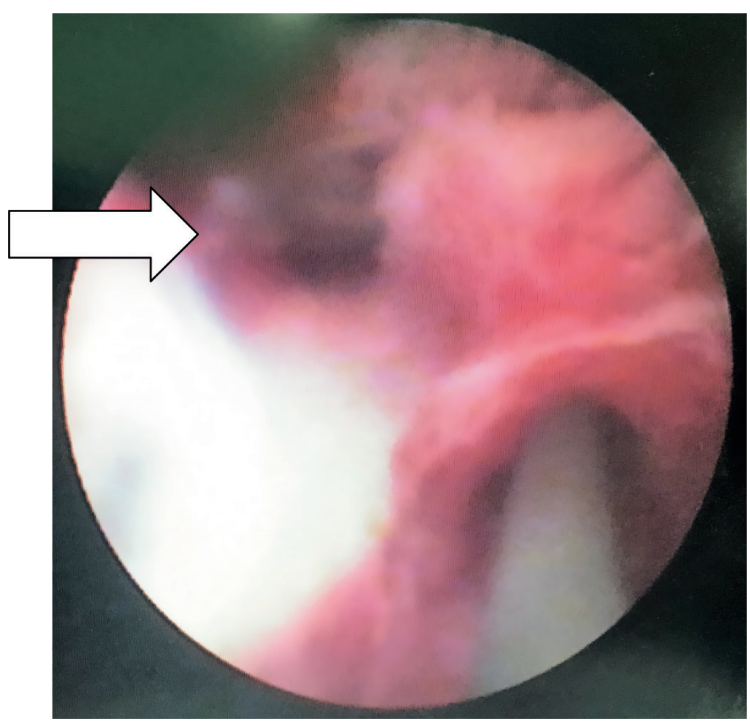

Figure-2: Endoscopic view of ureterovaginal fistula. Arrow showing fistula on the right side and guide-wire is in the proper ureteric lumen.

Both ends open double $\mathrm{J}$ stent of size $6 \mathrm{~F}$ was finally inserted by retrograde method. Foley catheter was removed after 48 hours.Patients were discharged within 72 to 96 hours after the surgery.

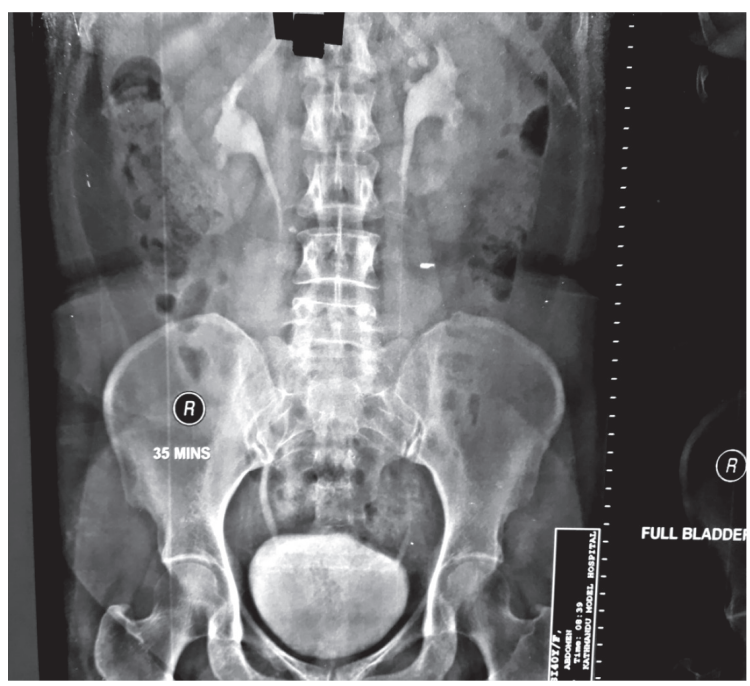

Figure-3: Post-operative contrast study of left UVF managed by retrograde DJ stenting. Patent Left ureter with normal Left kidney.

The DJ stent was removed 12 weeks after the surgery. Patients were followed up by ultrasonography (USG) of abdomen and pelvis after three months of removal of thestent which showed normalkidney without hydroureter proximal to fistula site. At 6 months of post-DJ removal, contrast study was done which showed patent ureter without stricture at fistula site [Figure-3], followed by yearly USG which showed normalkidney without hydrouretero-nephrosis. Follow up period ranged from 3 months to 60 months.

\section{DISCUSSION}

In iatrogenic uretero-vaginal fistula(UVF), mechanisms of ureteric injuries are laceration or transaction of ureter, blunt avulsion, crush injury, complete or partial suture ligation, and operative ischemic injury due to compromise in vascular supply of ureter and cautery injury. ${ }^{4}$ Iatrogenic ureteric injury often occurs in $0.5-2.5 \%$ of major gynaecological and obstetric surgical procedures which leads to formation of UVF. ${ }^{7}$

Gynaecological procedure like total abdominal hysterectomy wasthe most common cause (50\%) followed by cesarean section (being the most common obstetric procedure) causing iatrogenic ureteric injury. ${ }^{3,4}$ There is the risk of ureteric injury during different gynaecological and obstetrical surgery [Table-2]. In our patients, who had UVF, 57.14\% of patients had total abdominal hysterectomy (TAH), $28.57 \%$ patients had emergency LSCS and 14.29\% patients had total laparoscopic hysterectomy (TLH).

Table-2: Risk of ureteric injury in obstetrical and gynecological procedures (based on article of $\mathrm{Jha}^{\mathrm{et}} \mathrm{al}^{7}$ ).

\begin{tabular}{|l|l|l|}
\hline Sub-speciality & \multicolumn{1}{|c|}{ Procedure } & Incidence \% \\
\hline Obstetric & $\begin{array}{l}\text { Emergency Caesarean } \\
\text { section }\end{array}$ & $0.027-0.09$ \\
\cline { 2 - 3 } Gynaecological & Caesarean Hysterectomy & $0.5-8.0$ \\
\cline { 2 - 3 } & Abdominal Hysterectomy & $0.04-3.0$ \\
\hline Vaginal Hysterectomy & $0.02-0.47$ \\
\hline Laparoscopy & $\begin{array}{l}\text { Adnexectomy } \\
\text { Laparoscopically assisted }\end{array}$ & 2.9 \\
\cline { 2 - 3 } & $\begin{array}{l}\text { Laginal hysterectomy } \\
\text { vagina }\end{array}$ & \\
\hline
\end{tabular}

Iatrogenic ureteric injury depends on various factors, such as experience of the operating surgeon, surgical difficulty due to anatomical distortion of the ureter by various pathologies, adhesions due to previous surgeries, intra-operative massive hemorrhage and haphazard dissection at obscure surgical field. ${ }^{7,-11}$ Interestingly, ureteric injuries are often seen even in 
the most straightforward procedures.

It is difficult to diagnose ureteric injury intraoperatively due to anatomical proximity of distal ureter in relation with female genital tract along its course to the pelvis.Pelvic ureter passes lateral to utero-sacral ligament, cervix and fornix of vagina, so it is the most common site for injury during gynecological and obstetric procedures. The most frequently injured site are lateral to uterine vessels, base of infundibulo-pelvic ligament, the ureterovesical junction area close to the cardinal ligaments, the point where ureters cross the pelvic brim at the ovarian fossa, and at the level of uterosacral ligament.

Radiological studies have shown that in $10 \%$ of cases with cervical pathology, the ureter may lie as close as $5 \mathrm{~mm}$ lateral from the cervix which makes it very vulnerable for injury if careful dissection is not carried out. ${ }^{12}$ Many studies concluded that the most common site of ureteric injury is lateral to the uterine vessels $^{13}$, however, Daly et al ${ }^{9}$ report this to be at the ovarian fossa. During laparoscopic hysterectomy, most frequently the ureter is injured at the level of uterosacral ligaments. ${ }^{14}$

Around $70 \%$ of cases of UVF are diagnosed postoperatively from 1-4 weeks. ${ }^{1}$ Urine leak per vagina, flank pain and fever are the most common presenting symptoms. Haematuria, though a reliable indicator of injury to the urinary tract, is absent in approximately $30 \%$ of ureteric injuries. Urinoma formation, features of peritonitis/ileus, distended abdomen and urine leak via abdominal wound might be the presenting features in some cases. However, those typical symptoms might occur in only $50 \%$ of women with ureteric injuries. ${ }^{1,2}$

In our study, the commonest presenting symptom was constant urine leak per vagina besides normal micturition from day one to 23 day of primary surgery, associated with flank pain prior to urine leak in majority of cases. This finding is similar to the study by Rajamaheswari et al ${ }^{5}$ and Mandal et al. ${ }^{6}$ Management of UVF depends on the timing of diagnosis, etiology, length and site of injury, extent of causative procedure, and general condition of the patient.

The UVF has got the highest morbidity of the urogenital fistula because of its potential to cause urine incontinence, sepsis, and renal loss. ${ }^{15}$ Adequate history, detail physical examination, reviewing previous surgery operative notes, and appropriate radiological studies when combined together, candiagnosemost of the UVF earlier. ${ }^{3}$ In UVF, excretory urogram (IVU) or a computer tomography urogram (CTU) shows degree of ureteral obstruction with proximal ureteral dilation along with extravasation of contrast material in the pelvis or in the vagina. ${ }^{6}$ An oblique or lateral film may be necessary to differentiate the contrast in the bladder from that in the vagina. ${ }^{6,15}$ Cystoscopic evaluation of urinary bladder and upper tract evaluation should be compulsorily done in all cases of genitourinary fistula before considering any surgical intervention. Studies have shown that in approximately $12 \%$ of diagnosed cases of vesicovaginal fistula (VVF), concomitant distal ureteral injury or ureterovaginal fistula are also present. ${ }^{3,16-18}$ Our center's previous study ${ }^{19}$ also supports this evidence of UVF with concomitant VVF seen in 2 out of 15 cases.

According to the Organ Injury Scaling System developed by the Committee of the American Association for the Surgery of Trauma (AAST), ${ }^{20}$ ureteric injuries are classified as follows- grade I: haematoma, contusion or haematoma without devascularisation, grade II: laceration $<50 \%$ transaction, grade III: laceration $\geq 50 \%$ transaction, grade IV: laceration; complete transaction with < $2 \mathrm{~cm}$ of devascularisation and grade V: laceration; avulsion with $>2 \mathrm{~cm}$ of devascularisation. The other forms of injury being partial and complete transections (avulsion) injury. ${ }^{13}$ Once the injury occurs, urine follows the less resistant tract to vagina, owing to formation of UVF. ${ }^{6}$

Injury occurs most frequently in the distal third of the ureter $(51 \%)$, followed by the proximal third $(30 \%)$ and the middle third $(19 \%))^{21}$ In our study, all the patients had distal ureteric injury close to vesicoureteric junction leading to ureterovaginal fistula which justifies that distal third ureteric injury is most frequently encountered. Reason behind distal third/ pelvic ureter injury may be due to inattentive use of clamps or suture ligation of large tissue segments in the deep pelvis to control active bleeding, which is accordingly the only location at which a ureteral injury may result in UVF. ${ }^{3,15}$ The incidence of different forms of injury are complete 
transection, 61\%; excision, 29\%; ligation, $7 \%$ and partial transection $3 \% .^{21}$

Hanif et $\mathrm{al}^{22}$ and Liet $\mathrm{al}^{23}$ showed that the left ureteric injury was predominance over the right ureter. Our study also showed that majority of UVF was in the left side (64\%). Hypothesis behind this may be that operating surgeon being on right side and approaching for haemostasis while hemorrhage with inadvertent clamping under obscured vision. However other study favors for right ureter predominance. ${ }^{3,24}$ In conclusion it is hard to predict side predominance.

Therearemany publications regarding the management of UVF by endourological approach. Selzman et $\mathrm{al}^{3}$ showed that uretero-vaginal fistulas were managed successfully in all seven cases with retrograde DJ stenting. Choudhury et $\mathrm{al}^{16}$ in their study concluded that the undiagnosed ureteric injuries during various gynecologic and other pelvic surgeries may lead to ureterovaginal fistula. Surgical expertise along with availability of proper instrumentsand endoscopic ureteric stenting can be regarded as one of the most effective minimally invasive approach to manage ureterovaginal fistula. Al-Awadi et $\mathrm{al}^{25}$ showed a59.4\% success rate with DJ stenting in 75 patients with ureteral injuries. Turner et $\mathrm{al}^{26}$ showed a $50 \%$ success rate in 10 patients.

Liet $\mathrm{al}^{23}$ analyzed 46 patients undergoing UVF management and majority (45 patients) underwent management with retrograde DJ stenting for distal unilateral ureteric injury. Of the 45 patients operated, 16 had their DJ stents removed after 3-6 months, and 29 cases needed replacement every 6-12 months. Ten patients had recurrent stenosis, underwent ureteroscopic endo-ureterotomy or re-expansion with a balloon without further complications. They concluded that the endoscopy technique is effective treatment modality, less invasive and easily accepted by patients. Recurrent stenosis can be managed by ureteroscopic endo-ureterotomy or re-expansion with a balloon. In our series, none of the patients required re-stenting, endo-ureterotomy or balloon dilatation for failed fistula closure or ureteral stenosis. After diagnosis of ureterovaginal fistula, ureteroscopic assisted ureteric stenting should be attempted as early as possible. Successful ureteric stenting has got higher chances of spontaneous fistula closure which in turn may prevent other unnecessary surgeries and significantly reduce associated morbidities. The chance of fistula closure after stenting increases when there is maintained ureteral continuity along with normal appearing ureteric lumen distal to fistula site.

A study by Koukouras et $\mathrm{al}^{27}$ showed $56 \%$ success rate in 25 cases series of UVF. However, Ku et al ${ }^{28}$ reported $64.7 \%$ success rate in 17 patients andPatilet $\mathrm{al}^{29}$ reported $71.4 \%$ success rate in 14 patients. The results of our study are also comparable with abovementioned studies [Table-3].

Table-3: Comparison of outcome ofretrograde DJ stenting in ureterovaginal fistula.

\begin{tabular}{|l|c|c|}
\multicolumn{1}{|c|}{ Study } & Number of patients & Success rate (\%) \\
\hline Selzman et $\mathrm{al}^{3}$ & 7 & 100 \\
\hline${\text { Al- awadi et } \mathrm{al}^{25}}^{25}$ & 75 & 59.4 \\
\hline${\text { Turner et } \mathrm{al}^{26}}^{26}$ & 10 & 50 \\
\hline${\text { Koukouras et } \mathrm{al}^{27}}^{27}$ & 25 & 56 \\
\hline Ku et al & \\
\hline Patilet $\mathrm{al}^{29}$ & 17 & 64.7 \\
\hline Current study & 14 & 71.4 \\
\hline
\end{tabular}

According to various literatures success rates of these procedures vary from $6 \%$ to $100 \%$, although the overall success rate in most of the studies is around $50 \%$. $^{30,31}$

In our study, the success rate in fistula closure when ureteroscopic stenting was performed was $100 \%$, but these patients need to be followed up for longer duration. Out of 30 patients of UVF managed in our center, 14 patients $(46.66 \%)$ were successfully managed by endourological technique. In terms of fistula closure, all 14 patients managed by endourological technique had healed fistula by 3 months following stenting. Patients presenting earlier from the time of primary surgery had high chances of successful retrograde DJ stenting. This might be related with the fact that in early days of injury there is less tissue adhesions and scar formation so it will be easier to dilate the scar tissue or narrow part in the ureter and insert the guide wire through URS. The post-operative complications were however less in our study with majority (12 patients) of them had Clavien-Dindo grade I and 2 patients had recurrent urinary tract infection (Clavien-Dindo grade II). None of our patients developed recurrence of fistula andureteral stenosis requiring further endoscopic 
interventions till now. All cases are onregular follow up till date with normal renal function.

\section{CONCLUSIONS}

Both hysterectomy (open or laparoscopic) and Cesarean Sections can lead to ureteric injury and uretero-vaginal fistula. Endourological approach with retrograde DJ stenting was successful to heal ureterovaginal fistula and make patients continent. Three months of DJ stenting has shown successful results in terms of fistula closure without short-term morbidity.

\section{REFERRENCES}

1. Comiter CV, Vasavada SP, Raz S. Ureterovaginal Fistula. In: Stanton SL, Zimmern PE, editors. Female Pelvic Reconstructive Surgery. London: Springer; 2003.

2. Elabd S, Ghoniem G, Elsharaby M. Use of endoscopy in the management of postoperative ureterovaginal fistula. Int Urogynecol J Pelvic Floor Dysfunct.1997;8:188-90.

3. Selzman AA, Spirnak JP, Kursh ED. The changing management of ureterovaginal fistulas. J Urol.1995;153:626-8.

4. Al-Otaibi KM. Ureterovaginal fistulas: The role of endoscopy and a percutaneous approach. Urol Ann.2012;4:102-5.

5. Rajamaheswari N, Chhikara AB, Seethalakshmi K. Management of ureterovaginal fistulae: An audit. Int Urogynecol J 2013;24:959-62

6. Mandal AK, Sharma SK, Vaidyanathan S, Goswami AK.Ureterovaginal fistula. Summary of 18 years' experience. Br J Urol.1990;65:453-6.

7. Jha S,Coomarasamy A, Chan KK. Ureteric injury in obstetric and gynaecological surgery. Obstet Gynaecol. 2004;6:203-8.

8. Lewis G, de Bernis L, editors. Obstetric fistula: guiding principles for clinical management and programme development. Geneva: World Health Organization; 2006.

9. Daly JW, Higgins KA. Injury to the ureter duringgynecologic surgical procedures.SurgGynecol Obstet.1988;167:19-22.

10. Piscitelli JT, Simel DL, Addison WA. Who should have intravenous pyelograms before hysterectomy forbenign disease? Obstet Gynecol.1987;69:541-5.

11. Rajasekar D, Hall M. Urinary tract injuries during obstetric intervention.BJOG.1997;104:731-4.

12. Gemer O, Simonocsky A, Huerta M, KapustianV, Anteby E, Linov L. A radiological study on the anatomical proximity of the ureters and the cervix. Int Urogynecol J Pelvic Floor Dysfunct. 2007;18:991-5.

13. Ridley JH.Gynecologic Surgery: Errors, Safeguards,Salvage. Philadelphia: Lippincott Williams and Wilkins;1981.

14. Grainger DA, Soderstrom RM, Schiff SF, GlickmanMG, DeCherney AH, Diamond MP. Ureteral injuries at laparoscopy: insights into diagnosis,management, and prevention. Obstet Gynecol.1990;75:839-43.

15. Dowling RA, Corriere JN Jr, Sandler CM. Iatrogenic uretera injury. J Urol.1986;135:912-5.

16. ChodharyS,JainP,PalDK.Retrospective analysis of management of ureterovaginal fistula.SchJAppMedSci.2017;5 (4F):1674-8

17. Lee RA, Symmonds RE, Williams TJ. Current status of genitourinary fistula. Obstet Gynecol. 1988;72(3 Pt 1):313-9.
18. Fichtner J, Voges G, Steinbach F, Hohenfellner R. Ureterovesicovaginal fistulas. Surgery, Gynecol Obstet. 1993;176(6):571-4.

19. Upadhyay AM, Kunwar A, Shrestha S, Pradhan HK, Karki A, Dangal G. Managing Ureterovaginal Fistulas following Obstetric and Gynecological Surgeries. J Nepal Health Res Counc. 2018;16(2):233-8

20. The American Association for the Surgery of Trauma.Injury Scoring Scale - A Resource for Trauma Care Professionals. [Assessed on 19 May 2020].Available at https://www.aast. org/library/traumatools/injuryscoringscales.aspx

21. Berkmen F, Peker AE, Alago 1H, Ayyildiz A, Arik AI, Basay S. Treatment of iatrogenic ureteral injuries during various operations for malignant conditions. J Exp Clin Cancer Res. 2000;19:441-5.

22. Hanif MS, Saeed K, Sheikh MA. Surgical management of genitourinary fistula. J Pak Med Assoc. 2005;55:280-4.

23. Li X, Wang P, Liu Y, Liu C. Minimally invasive surgical treatment on delayed uretero-vaginal fistula.BMC Urology. 2018;18:96

24. Arasu C, Ramasamy N, Kumaresan N. Early Endoscopic Management of Ureterovaginal Fistula: A Prospective Study. Int J Sci Stud. 2016;4(2):191-3.

25. Al-Awadi K, Kehinde EO, Al-Hunayan A, Al-Khayat A. Iatrogenic ureteric injuries: Incidence, aetiological factors and the effect of early management on subsequent outcome.IntUrolNephrol. 2005;37(2):235-41.

26. Turner WH, Cranston DW, Davies AH, Fellows GJ, Smith JC. Double $\mathrm{J}$ stents in the treatment of gynaecological injury to the ureter. J R Soc Med. 1990;83(10):623-4

27. Koukouras D, Petsas T, Liatsikos E, Kallidonis P, Sdralis EK, Adonakis G, et al. Percutaneous minimally invasive management of iatrogenic ureteral injuries. J Endourol. 2010;24(12):1921-7.

28. Ku JH, Kim ME, Jeon YS, Lee NK, Park YH. Minimally invasive management of ureteral injuries recognized late after obstetric and gynaecologic surgery. Injury. 2003;34(7):480-3.

29. Patil SB, Guru N, Kundargi VS, Ranka K. Post hysterectomy ureteric injuries: Presentation and outcome of management. Urol Ann. 2017;9(1):4-8.

30. Badlani GH, Ridder JMK, Mettu JR, Rovner ES. Urinary tract fistulae. In: Wein JA, editor. Campbell Walsh Urology. 11th ed. Philadelphia: Saunders Elsevier; 2016.

31. Narang V, Sinha T, Karan SC, Sandhu AS, Sethi GS, Srivastava A, et al. Ureteroscopy: Savior to the gynecologist?-Ureteroscopic management of post laparoscopic assisted vaginal hysterectomy ureterovaginal fistulas. J Minim Invasive Gynaecol.2007; 14(3):345-7. 